\title{
Urinary thioether output as an index of occupational chemical exposure in petroleum retailers
}

\author{
J K STOCK, B G PRIESTLY \\ From the Department of Clinical and Experimental Pharmacology, University of Adelaide, Adelaide, South \\ Australia 5000
}

Petroleum is a complex mixture of lipophilic chemicals, some of which are likely to be substrates for the microsomal mixed function oxygenases. Petroleum retailers, by virtue of their occupational exposure potential, are a group likely to receive relatively heavy exposure to petroleum products in comparison with the general public.

Urinary thioether output may provide a simple, non-invasive technique for identifying occupational chemical exposure. ${ }^{12}$ The technique exploits the fact that conjugation with glutathione, followed by urinary elimination as mercapturates, is a significant metabolic clearance pathway for electrophilic chemicals and, in particular, for putatively toxic metabolites of the microsomal mixed function oxygenase system. Raised thioether output has been confirmed for several occupations associated with potential exposure to such chemicals. ${ }^{3-6}$

Induction of the microsomal oxygenases is a common response to the ingestion of lipophilic chemicals. Since hepatic microsomes from rats exposed to petroleum vapours were found to have induced activity towards a range of cytochrome $\mathrm{p} 450$ substrates, ${ }^{7}$ it was reasonable to interpret the faster clearance of antipyrine in a cohort of petroleum retailers ${ }^{7}$ to result from occupational exposure to petroleum, although it was not possible to confirm exposure more directly using indices based on petroleum components such as benzene or lead and shown by others ${ }^{89}$ to be sensitive to petroleum exposure.

This study was undertaken to assess the utility of the urinary thioether technique to detect occupational chemical exposure in petroleum retailers. Since attendant operated pumps have been supplanted in many outlets by self-service pumps, it was of some interest to determine whether this difference in retailing practice was reflected in the occupational exposure patterns.

Accepted 13 May 1986

\section{Methods}

Forty three male and five female employees (aged 16-53 (mean 29, SD 10)) at 25 Adelaide suburban petrol vending stations took part in the study. Thirteen were employed in self service stations. All had worked in the industry as petrol pump attendants or garage mechanics, or both, for more than a year. They were asked to collect two urine samples during a midweek working day — one prework sample between 0600 and 0700 and one postwork sample between 1900 and 2000. Samples were stored in the freezer until analysis. A short questionnaire giving details of diet, medications taken, cigarette consumption, and employment duties was completed by each subject ato the time of sample collection. Urine samples were analysed for both thioether and creatinine concen tration as follows.

\section{THIOETHER}

Urinary thioether concentration was determined after acidification and ethylacetate extraction by colorimetric assay, as described by van Doorn et al. ${ }^{1-3}$ Concentrations were expressed as $\mu$ moles thioether relative to creatinine concentration (mmoles) to minimise any variation due to fluctuations in urine output.

\section{CREATININE}

Creatinine concentration was determined by the method of Yatzidis. ${ }^{10}$

\section{STATISTICS}

Work related changes (am to pm differences) in individuals were analysed by the Wilcoxon matched pairs, signed rank test, 2 tail. The rises in urinary thioether output in smokers versus non-smokers, in pump attendants versus self service outlets, and the influence of workshop duties were compared with the Mann-Whitney $U$ test. The interaction between smoking and work related thioether output was assessed by a 2 way ANOVAR. 


\section{Results}

Urinary thioether concentrations in petrol retailers at the end of a normal working day were significantly raised when compared with the morning sample $(\mathrm{p}<$ 0.001 ) (figs 1 and 2 ). The differences were greater ( $p$ $<0.001)$ in attendant operated outlets than in self service outlets (fig 1). Whereas most of the self service employees were solely engaged in remote operation of the cash register and pump controls, some also undertook mechanical workshop duties. In neither self service nor attendant operated stations, however, was there any indication that workshop duties were a significant factor in increasing urinary thioether output (fig 2). The only factor, other than driveway exposure to petroleum products, that could be identified as being associated with raised thioether output was cigarette smoking. Cigarette smokers

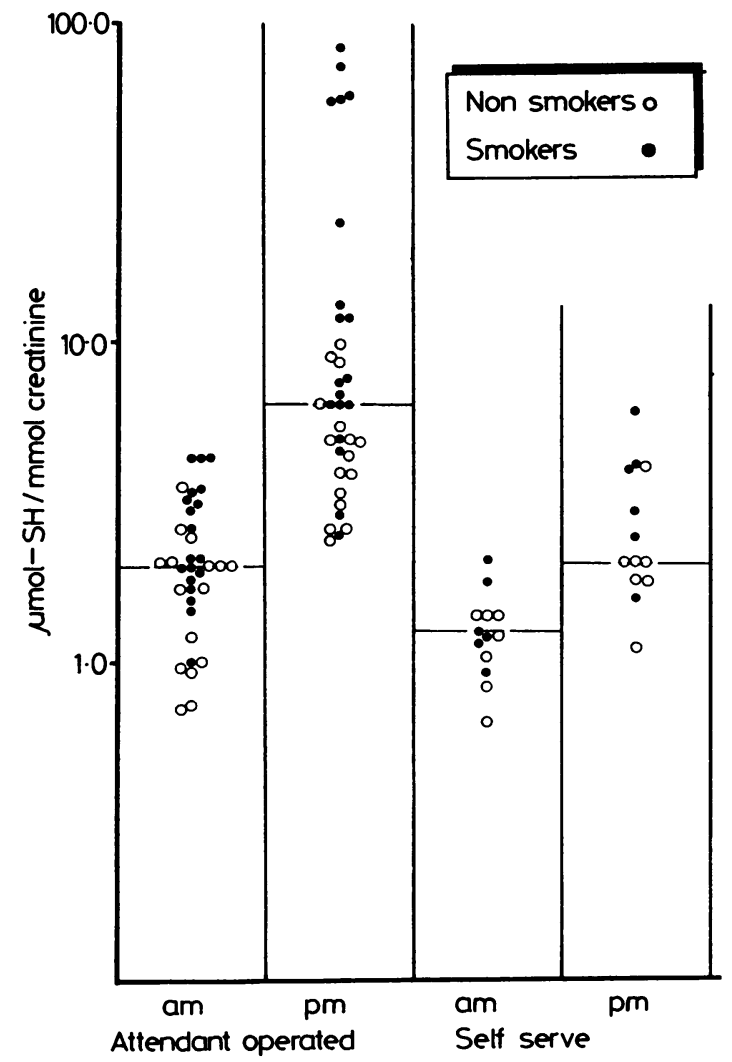

Fig 1 Pre-and postwork urinary thioethers in petrol retailers and smoking habits, grouped according to nature of pump operating procedures. Bars represent median values.

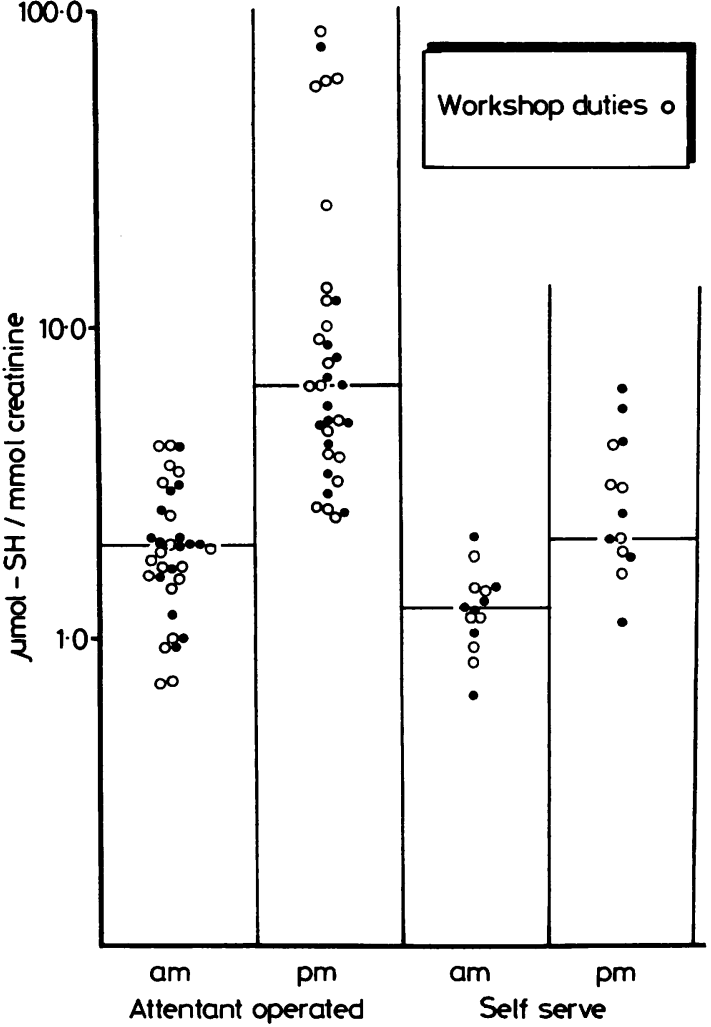

Fig 2 Pre-and postwork urinary thioethers in petrol retailers, grouped according to nature of pump operating procedures and to whether or not they also undertook workshop duties. Bars represent median values.

excreted higher levels of thioethers in both prework ( $p$ $<0.005)$ and postwork ( $\mathrm{p}<0.001)$ samples, and there was also a significant interaction between smoking and work related thioether output $(p=0.01)$.

\section{Discussion}

These results confirm that raised urinary thioether output attributable to occupational chemical exposure occurs in the petroleum retailing industry, in common with findings in other industries. ${ }^{3-7}$ In the strict sense the technique should be viewed as a qualitative, rather than a quantitative, indicator of exposure. The estimated thioether concentrations are based on thiol determination after hydrolysis of an unknown mixture of thioethers in urine, and neither the identity of the metabolites, nor their quantitative recovery, can be assumed. While it has been shown that this non-specific technique detects dose related increases in output from certain model substrates in 
animals, ${ }^{11-13}$ the human exposure model is more complex.

Given the non-specific nature of the assay, it is not possible to identify the chemical components of the occupational environment that account for the raised thioether output. Nevertheless, the observations that (1) raised thioether output is not associated with performance of workshop duties, and (2) isolation from driveway pump operation in self service outlets reduces the magnitude of the increase leads to the strong implication that inhalation of petrol vapour is the main source of thiometabolisable substrates.

Metabolic pathways leading to the formation of the urinary thiothers need not necessarily involve an electrophilic intermediate such as an epoxide of the microsomal oxygenases. Petroleum contains such substances as aliphatic and aromatic halides and alpha-beta unsaturated ketones, many of which undergo direct or glutathione transferase catalysed conjugation with glutathione. The direct and indirect pathways cannot be differentiated in our data, although the apparent interactive effect of cigarette smoking may favour an oxidative step in the dominant pathway on the grounds that smoking is known to induce microsomal oxygenase activity. ${ }^{14}$

\section{Requests for reprints to: Dr B G Priestly.}

\section{References}

1 Van Doorn R, Leijdekkers CH-M, Bos RP, Brouns RME, Henderson PTH. Detection of human exposure to electrophilic compounds by assay of thioether detoxication products in urine. Ann Occup Hyg 1981;24:77-92.
2 Van Doorn R, Bos RP, Leijdekkers CH-M, Wagenaas-Zegers C MAP, Theuws JLG, Henderson PTH. Thioether concentration and mutagenicity of urine from cigarette smokers. Int Arch Occup Environ Health 1979;43:159-66.

3 Van Doorn R, Leijdekkers CH-M, Bos RP, Brouns RME, Henderson PTH. Enhanced cxcretion of thioethers in urine of operators of chemical waste incinerators. $\mathrm{Br} J$ Ind Med 1981;38:187-90.

4 Vainio H, Savolainen H, Kilpikari I. Urinary thioether of $\bar{C}$ employees of a chemical plant. Br J Ind Med 1978;35:232-4.

5 Kilpikari I. Correlation of urinary thioethers with chemical exposure in a rubber plant. Br J Ind Med 1981;38:98-100.

6 Stock JK, Priestly BG. Urinary thioether excretion as an index of occupational exposure to chemicals. Studies in petrol station attendants and fibreglass workers. Clin Exp Pharmacol Physiol 1982;9:421.

7 Harman AW, Frewin DB, Priestly BG. Induction of microsomal drug metabolism in man and in the rat by exposure to petroleum. $\mathrm{Br} J$ Ind Med 1981;38:91-7.

8 Sherwood RJ. Evaluation of exposure to benzene vapour during the loading of petrol. Br J Ind Med 1972;29:65-9.

9 Lob M. Apropos of leaded gasoline. II Comparative study of lead in blood, urinary lead and urinary porphyrins in various groups of the people of Lausanne (office workers, garage mechanics, policemen). Zeitschrift fur Praeventivmedizin 1965;10:172-6.

10 Yatzidis $H$. New method for the direct determination of "true" creatinine. Clin Chem 1974;20:1131-4.

11 Priestly BG, Stock JK. Urinary thioether excretion as an index of occupational exposure to chemicals. Studies in an animal model. Clin Exp Pharmacol Physiol 1982;9:420-1.

12 Rozman K, Summer KH, Rozman T, Greun H. Elimination of thioethers following administration of naphthalene and diethylmaleate to the rhesus monkey. Drug Chem Toxicol 1982;5:265-75.

13 Van Doorn R, Bos RP, Brouns RME, Leijdekkers CHM, Hen derson PTH. Effect of toluene and xylenes on liver glutathion and their urinary excretion as mercapturic acids in the rat. Arch Toxicol 1980;43:293-304.

14 Van Cantfort J, Gielen JE. Ontogenetic variation in rat liver, lun and kidney monooxygenase induction by low doses of benzo(a)pyrene and cigarette smoke condensate. $\mathrm{Br} J$ Cancer 1981;44:902-10. 